thought in a way that made men doubt whether he would ever succeed to the highest place. And what things have happened since then! What responsibilities he has accepted! What must be the strength of a man who at seventy-five, in spite of such foes and forces and even failures, can hold the prize of the politic ul game as he holds it! We are speaking apart from all political questions and issues ; we are speaking from a physiological standpoint, and we pronounce the physical and mental power displayed by Mr. Gladstone in the last fortnight in Scotland, after five years of scarcely paralleled labour, to be a piece of veritable athleticism worthy the study of young men, and a fit subject of pride to the nation.

\section{PERFECT FILTERS.}

THE excellent idea of turning to account for sanitary purposes the simple method used by M. Pasteur for separating microbes from their medium of culture has suggested itself to II. Chamberlan. He finds that even the most impure water, after filtration through a porous porcelain tube, is perfectly freed from germs and microbes. Under a pressure of two atmospheres twenty litres of water per day can be obtained from a tube 20 metre in length and 025 metre in diameter. Tubes so used can be cleaned by plunging them in boiling water or heating them in a flame till the organic matter coating the exterior is destroyed. He proposes, therefore, that porous porcelain vessels should be used as filtering media, the external surface being exposed to the impure water.

\section{OSSEOUS SUTURE FOR FRACTURED PATELLA.}

ON this subject, Professor L. Gosselin expresses himself, in the August number of the Archives Génerales de Médecine, in the following terms:- "In his thesis on the treatment of transverse fractures of the patella, by arthrotomy and osseous suture, M. Diverneresse has published the fol. lowing statistics: Eighty-eight cases, with five deaths; two suppurations, followed by amputation of the thigh ; fifteen suppurations, followed by anchylosis. It is irrational to follow a plan yielding such results in treating an injury which, under good and patient management, is unattended with any such consequences."

\section{OPEN SPACES IN LONDON.}

IT is, perhaps, not yet too late to remind both the Ecelesiastical Commissioners and the Metropolitan Board of Works that one of their most urgent duties, considering the present portentous growth of London, is to preserve, and, if necessary, to restore, at whatever cost, open spaces. Both of these authorities will deserve the gratitude of their contemporaries and of posterity by realising this part of their duty, which we take leave to say is in the greatest danger of being overlooked, with disastrous consequences.

\section{THE HOSPITAL SATURDAY FUND.}

IT is too soon to know the success of the present collection as a whole, but we may express our satisfaction at the street collection, exceeding by $£ 500-£ 2800$ against $£ 2300$ - that of last year, in spite of the wetness of the weather. With the exception of a systematised weekly contribution, noticed elsewhere, the sums from manufactories, \&c., seem to us still inadequate.

ACCORDINg to MM. Treille and Straus, the comma bacillus is not special to cholera, for they have found the same bacillus in the dejecta of patients suffering from the diarrhea of Cochinchina, or, rather, the diarrhcea of hot countries.
The Local Government Board have issued fresh orders as to the importation of rags. One renews the previous order for France, and makes it applicable to the end of this month, and an order for Italy applies for the same period. As yet no such order has been issued as regards Spain. Under these orders sanitary authorities or their authorised officers can require the disinfection or destruction of any rags which it is desired to land, unless satisfactory evidence is forthcoming that they have not arrived from an infected locality. They can also refuse to allow the rags to be landed at all.

Messrs. Crookes, OdLing, and TIDy, reporting to Colonel Sir Francis Bolton, official water examiner for the metropolis, on the composition and quality of daily samples of the water supplied to London during August, state that of the 168 samples derived from the seven mains of the metropolitan water companies taking their supply from the Thames and the Lea " the whole were, without exception, clear, bright, and well filtered."

THE Ophthalmological Congress, which had been appointed to meet in Turin from the 15th to the 20 th inst., has been deferred for the present, in consequence of the deplorable insanitary conditions of the Italian peninsula.

THE death is announced of Mr. J. J. Woodward, Surgeon, United States Army, the well-known microscopist.

A Memorandun on THE

\section{"COMMA-SHAPED BACILLUS," ALLEGED TO} BE THE CAUSE OF CHOLERA.

BY SURGEON-MAJOR TIMOTHY RICHARDS LEWIS, M.B., ASSISTANT PROFESSOR OF PATHOLOGY, ARMY MEDICAL SCHOOL.

WITH a view of studying the phase which the cholera question has now entered upon, in consequence of the publication of the results of the investigations of the German Cholera Commission in Egypt and India, I availed myself of the opportunity which the present vacation at the Army Medical School afforded of proceeding to Marseilles, where the disease has been prevalent since the end of June. Sir Joseph Fayrer was so kind as to enlist for me the valuable assistance of Dr. Le Roy de Méricourt, Médecin en Chef of the French Navy, who, in various ways, did his utmost to further my wishes. Dr. Marroin, the Chief of the Sanitary Department in Marseilles, was so good as to introduce me to the authorities of the Pharo Hospital, where the cholera cases are treated, and where, with the permission of the principal medical officer, Dr. Trastour, I was able to renew my acquaintance with the disease, and to collect material for studying afresh the microscopy of the intestinal dis. charges.

Before, however, referring to the results of my own observations, it will be convenient to epitomise the published history of the German Commission; to point out the salient features of the results of their investigations in Egypt and in India; and to make a few brief comments on such of the circumstances and conclusions as appear to call for notice. Shortly after the arrival of the Commission in Egypt, Dr. Robert Koch reported, on behalf of himself and his colleagues, that no special micro-parasites had been discovered in the blood, the lungs, the spleen, the kidneys, or in the liver in cholera, but that the intestinal mucous membrane was permeated by certain bacilli which nearly resembled in size and form the bacilli found in glanders. As is well known these bacilli are straight, and are, in fact, uncommonly like the ordinary microphytes associated with decay. Dr. Koch also states in connexion with this subject that he had, previous to proceeding to Egypt, found similar bacilli in the intestinal mucous membrane of four natives of India, but that he had then looked upon them as due to merely post-mortem changes. When he came to Egypt, 
however, and found these same bacilli in the intestines of perfectly fresh cases, he felt that an important link was furnished towards establishing the identity of the disease in Egypt with Indian cholera.

It is bighly probable that the specimens from India which Dr. Koch had examined were those which were sent, at the request of the Imperial Health Department in Berlin, hy the Sanitary Commissioner with the Government of India. These consisted of numerous dry-cover glass specimens of blood which I had collected frotn several cholera patients, and of portions of the viscera of four natives who had died of the disease. All these were examined by me before they were despatched, and portions of each were reserved for further study. I had heard nothing further of them, hnt the publication of the remarks above referred to in Dr. Koch's Report of September 17th, 1883, from Alexandria, recalled them to my mind, and I was glad to infer that my own negative results had been confirmed in Berlin. As already observed, no importance had been originally attached to the organisms which were present in the intestinal mucosa. Daring the last six months I have examined hundreds of stained microtome-sections of these four, and of other specimens of cholera intestines in my possession, and have found that when the mucosa is infiltrated with microphytes at all they are either micrococci, bacteria, or long-oval, and straight bacilli.

In the report of the Commission, dated Calcutta, February 2nd, 1884, Dr. Koch, however, announces for the first time that the specific. bacillus of cholera is curved or comma-shaped, and not straight, so that apparently it had become necessary to abandon the microbe first organisms. This is a condition, however, which, I under stand, is exceedingly rare. On the other hand, I have seen samples of choleraic dejecta in which totally different organisms prevailed to a like exelusion of others; and in one instance at Marseilles spirilla of various sizes and forms were the most conspicuous of the micro-organisms present. So far, therefore, the selection of the comma-shaped bacilli as the materies morbi of cholera appears to be entirely arhitrary.

Dr. Koch and his colleagues have adduced no evidence to show that they are more pernicious than any other microbe; indeed, as a matter of fact, the sole argument of any weiuht which has been brought forward in favour of the comma-shaped bacillus being the cause of cholera is the circumstance that it is more or less prevalent in every case of the disease, and that the German Cnmmission had not succeeded in finding it in any other. With regard to the suggestion that the cholera process may in some way favour tlie growth of these bacilli, and that these are not necessarily the canse of the disease, Dr. Koch remarks, in the report from Calcutta above cited, that such a view is untenable, inasmuch as it would have to be assumed " that the alimentary canal of a person stricken with cholera must have already contained these particular bacteria; and, seeing that they have invariably been found in a comparatively large number of cases of the disease both in Egypt and India-two wholly separate countries, -it would be necessary to assume, further, that every individual must harbour them in his system. This however, cannot be the case, becanse, as already stated the comma-like bacilli are never found except in cases of cholera."

Length AND Width (IN Micro-millimetres*) of Comma-shaped Bacillis in Choleraic Material and SeCRETIONS OF THE MOUTH IN HeALrh.

\begin{tabular}{|c|c|c|c|c|c|c|c|c|}
\hline \multirow{3}{*}{ Numbers. } & \multicolumn{5}{|c|}{ Choleraic Material. } & \multirow{2}{*}{\multicolumn{3}{|c|}{$\begin{array}{l}\text { SECRETIONS OF THE MOUTH IN } \\
\text { HEALTH. }\end{array}$}} \\
\hline & \multicolumn{3}{|c|}{ Alvine discbarges. } & \multirow{2}{*}{$\begin{array}{l}\text { Intestinal } \\
\text { contents. } \\
\text { [autopsy.] }\end{array}$} & \multirow{2}{*}{$\begin{array}{c}\text { Cultivation } \\
\text { in agar-agar jelly. }\end{array}$} & & & \\
\hline & I. & II. & III. & & & I. & II. & III. \\
\hline 1 & $\begin{array}{c}\mu \\
2.4 \times 0.40\end{array}$ & $2 . \stackrel{\mu}{2.60} \times 0.60$ & $1 \cdot \stackrel{\mu}{\times 0} \times 0.25$ & $\begin{array}{c}\mu \\
2.0 \times 0.40\end{array}$ & $\stackrel{\mu}{\mu} 1 \cdot 6 \stackrel{0}{x} \cdot 40$ & $2 . \stackrel{16}{x}^{h} 0.50$ & $\begin{array}{c}\mu \\
1.4 \times 0.35\end{array}$ & $\begin{array}{c}\mu \\
1.5 \times 0.500\end{array}$ \\
\hline 2 & $26 \times 0.40$ & $2.5 \times 0.65$ & $1.8 \times 0.35$ & $12 \times 0.40$ & $1.4 \times 0.60$ & $1.3 \times 035$ & $2 \cdot 0 \times 0 \cdot 40$ & $13 \times 0.50$ \\
\hline 3 & $20 \times 0.50$ & $32 \times 0.70$ & $2.0 \times 0.60$ & $1.5 \times 045$ & $18 \times 0.50$ & $1.6 \times 0.40$ & $1 \cdot 7 \times 0 \cdot 40$ & $1.0 \times 0.30$ \\
\hline 4 & $2 \cdot 2 \times 0.45$ & $30 \times 0.70$ & $3.0 \times 0.70$ & $13 \times 060$ & $20 \times 0.50$ & $12 \times 035+$ & $1 \cdot 3 \times 0.45$ & $1.2 \times 0.40$ \\
\hline 5 & $2.8 \times 0.35 \neq$ & $2.5 \times 0.60$ & $2 \cdot 2 \times 0.50$ & $2 \cdot 1 \times 0.50+$ & $2 \cdot 6 \times 0.45$ & $22 \times 0.65$ & $21 \times 0.50$ & $2.7 \times 0.50$ \\
\hline 6 & $1.5 \times 0.35$ & $20 \times 0.50$ & $1.6 \times 0.40$ & $12 \times 050$ & $1 \cdot 1 \times 035$ & $20 \times 0.40$ & $2.8 \times 0.40 \dagger$ & $1.4 \times 0.55$ \\
\hline
\end{tabular}

* One Micro-millimetre $(\mu)=\cdot 001$ millimetre $\left[={ }_{25} 500^{\prime \prime}\right]$

† S-shaped comma bacilli.

fixed upon. Assuming that the four specimens from natives of India which had been examined by Dr. Koch were those which passed through my hands, the evidence they furnish seems to be in accordance with this view, as in not one of them have I been able to detect any invasion by unmistakable "commas," though at least one of the specimens may fairly be characterised as abundantly infiltrated (in the manner described by Dr. Koch) by straight (and as I prefer to call them) putrefactive bacilli. Judging from my own experience, therefore, any extensive infiltration of the intestinal mucous membrane in cholera by comma-shaped bacilli must be exceedingly rare; and this, I believe, is likewise the experience of the members of the late French Cholera Commission, MM. Straus, Roux, and Nocard, whose acquaintance I had the pleasure of making at M. Pasteur's laboratory on my return through Paris.

Whilst at Marseilles I had, as already stated, opportunities of observing numerous specimens of choleraic excreta, and found that comma-shaped bacilli were, more or less conspicuously, present in all of them, though in some instances more than one slide had to be examined before any could be satisfactorily detected. It may also be mentioned that some of the discharges in which these organisms were present manifested an acid reaction when tested with litmus paper. As Dr. Koch bimself remarks, the proportion which the comma. shaped bacilli bear to other organisms in the dejecta varies greatly. In some instances only one or two specimens are to be found in the field of the miscroscope, while in others they are very numerous, and Drs. Nicati and Rietsch (who are at present engaged in the study of the disease at Marseilles) were so kind as to show me a specimen of choleraic materia they had obtained from the small intestine, in which the "commas" existed almost to the exclusion of all other
Had Dr. Koch and his colleagues submitted the secretions of the mouth and fauces-the very commencement of the alimentary canal-to a careful microscopic examination of the same kind as that to which they have submitted the alvine discharges, I feel persuaded that such a sentence as the foregoing would not have been written, seeing that comma-like bacilli identical in size, form, and in their reaction with aniline dyes, with those found in choleraic dejecta, are ordinarily present in the mouth of perfectly healthy persons.

[Since this memorandum was submitted I have observed that Dr. Koch states, in his recent address on the subject, that after his return to Berlin he had examined, amongst other things, the secretions of the month for commashaped bacilli, but had found none; and, further, that he had consulted persons of much experience in bacterial researches as to whether they had ever seen such organisms, and was told that they had not. It may be of assistance to future observers if $I$ give the dimensions of half-a-dozen comma-shaped bacilli, as found in each of the following: (a) In the alvine discharges of three cholera-affected persons ; (b) in the small intestine of a person who had died of the disease, and in whom they existed almost to the exclusion of other organisms ; $(c)$ in a cultivation of them in agar-agar jelly; and $(d)$ in the secretions of the mouth of three healthy persons, ranging from four to fifty years of age. The measurements were made (with the valuable assistance of Mr. Arthur E. Brown, B.Se. Lond, under a magnifying power of 1000 diameters, a Powell and Lealand's $\frac{1}{16}$ th of an inch oil-immersion lens, with a wide angle condenser, being used.] See Table, supra.

There is no difficulty in putting this statement to the test; and to any one acquainted with the methods ordinarily 
adopted for staining and mounting fungal organisms of this character, no special directions need be given. The procedure followed by me to demonstrate these "commas" in the saliva is precisely that adopted for finding them in the dejections. A little saliva should be placed on a cover-glass (preferably in the morning before the teeth are brushed), and allowed to dry thoroughly, either spontaneously or aided by a gentle heat. The dry film thus obtained should be floated for a minute or two with one or other of the ordinary solutions of aniline dyes adopted for such purposes, such, for example, as fucbsine, gentian-violet, or methylene blue. The cover should then be gently rinsed with distilled water, and the film re-dried thorougbly. The preparation may now be mounted in dammar varnish or Canada balsam dissolved in benzol, and should be examined under a $\frac{1}{12}$ th or $\frac{1}{16}$ th of an inch oil-immersion lens.

As in choleraic discharges so in the saliva, the number of comma-shaped bacilli will be found to vary greatly in different persons, and at different times in the same person. Sometimes only one or two "commas" will be seen in the field, at others a dozen may be counted, and, occasionally, little colony-groups of them may be found scattered here and there throughout the slide.

It may be remarked in passing, and as bearing upon what has been already said regarding the general absence of comma-shaped bacteria from the intestinal mucosa itself, that they do not appear to manifest any special tendency for attacking the decaying epithelial scales of the mouth, but that, on the contrary, they are for the most part found free in the fluid, the epithelium being studded with other bacterial forms.

Persons who have not been in the habit of examining dried saliva-films will probably be surprised at the number and variety of the organisms which are, more or less, constantly to be found in the mouth, and especially at the number of spirilla with wbich the fluid is generally crowded.

The alvine discharges in cholera sometimes swarm with precisely similar spiral organisms, and, indeed, as has long been known, the fluid exuded into the intestines in this disease is peculiarly suitable for the growth of these and allied microbes. But, so far as my own experience-dating from 1869-of the microscopic examination of such a fluid goes, all the microphytes ordinarily found in it are like wise to be found, to a greate: or less extent, in the secretions of the mouth and fauces of unaffected persons. And with reference to the comma-like bacilli found in cholera, to which such virulent properties have been ascribed, I shall continu to regard them as identical in their nature with those ordinarily present in the saliva until it has been clearly demon strated that they are physiologically different.

\section{INSANITY IN NEW SOUTH WALES.}

IN his report for the year 1883 , Dr. Norton Manning, the Inspector-General of the Insane for New South Wales, gives the number of insane persons in the colony on Dec. 31st as 2403-viz., 1474 male and 929 female. This is an actual increase, as compared with the same date in 1882, of $96-$ 44 males and 52 females; but the rate of increase among the insane in proportion to the general population is stated to be somewhat less than usual. The returns given show that, "though during the ten years from 1864 to 1873 there was a considerable increase in the proportion of insane persons under care, and in the number admitted, there has been little or no increase during the last ten years either in the accumulated cases or in the admissions or "occurring cases' in proportion to the general population, and that the 'burden,' as it is fitly called, of insanity, is at a standstill." A comparative statement is made as regards the proportion of insane to population in the colony and in England. From this it appears that in England there has been a steady increase in the proportion from the year 1864, when it was 1 insane person in 457 of the population, down to the year 1882 , when it was 1 in 348 . It also appears that a general, though less steady, increase has taken place in the colony from $l$ in 399 in the year 1864, to 1 in 354 in the year 1882 At the end of the year 1881 the proportion stood at 1 in 352 both in the colony and in the mother country, a point which cannot fail to give interest to the comparative statistics in years to come. The insane in New South Wales are distributed in varying proportions through five hospitals for the insane and one licensed house. The hospitals are overcrowded, aud they contain as many as 232 in excess of the 2025 for whom accommodation is provided. The inspector-general is taking measures to remedy this unwholesome state of affairs, which is in a great measure due to the accumulation of aged and quiet patients, who in Great Britain are ordinarily provided for in workhouses. The percentage of recoveries on admissions and readmissions for the year was 40.7 , and the percentage of deaths on the average number resident was $66-$ males, $7 \cdot 7$; females, $5 \cdot 0$.

There were 476 admissions and readmissions during the year; and in only ten, or a little over 2 per cent., of these was hereditary influence ascertained. This is a small pro portion, and if an explanation were looked for, it might be found in the absence of relatives who could give information regarding individual waifs and strays who wander "far from their home," and are unable to give any reliable account of themselves or of their belongings. And, indeed, a reference to Table 9 seems to bear out this idea, for, from figures there given, only 23 per cent. of the entire insane population were natives of New South Wales, leaving a burdensome margin for the immigrant population, largely drafted from the rest less and wandering element of humanity, and represented by individuals who too often, apparently, arrive by sea, if they are not actually shipped, in a state of positive insanity. The report states that atter a lengthy correspondence the French Government have agreed to retain and provide for the insane persons of British nationality who become insane in New Caledonia, in the same way as has been done for years past by the Government of New South Wales in regard to persons of French nationality who are thrown upon their hands. During the year, thirty patients had been discharged as relieved to the care of friends; but it has not yet been found practicable to take any steps towards " boarding out" patients, or placing them with strangers paid for their main. tenance. The circumstances of colonial life, especially when of the "bush" type, the absence of suitable village homes, and the relations of labour and wages, combine to form a group of obstacles to the adoption of the system, and these obstacles are not likely to be readily overcome. The number of escapes was thirty-one, and all, with one exception, were recaptured within fourteen days, the great majority having had a run of less than twenty-four hours.

The accidents and injuries do not appear to have been numerous and none of them were fatal. There was only one suicide ; in the case of a male patient who cut his throat with a piece of glass bottle. With regard to restraint, we are informed that it is never used without the direct order of a medical officer, except in institutions without a resident medical officer, where the superintendent may place a patient in restraint with the subsequent'sanction of the visiting medical officer. The propriety of permitting any layman to place a sick person, or an individual under medical treatment, in a camisole or strait-jacket cannot be upheld, and it would be well that such an anomalous exception were done away with. Restraint is not, however, very largely used, for the returns sent to the inspector-general show that the amount never exceeds one patient in restraint out of every 400 , and is frequently much less, and that in half of the cases it is employed for surgical reasons. The inspectorgeneral sums up his experience of restraint in the following terms: "Under proper regulations it has a useful place in the treatment of insanity, and I hold that the position taken by the physicians of American hospitals is in this respect more philosophical and more humane than the extreme views held by some alienists in Great Britain." No general statement is given of the amount of seclusion that was had recourse to, although it may be gleaned that in some of the asylums, at least, it is not extensively made use of. The average woekly cost per patient in hospitals for the insane in New South Wales is $12 s .5 \frac{7}{8} d$, being $2 s$. greater than that in English borough asylums, which is $10 s .5 \frac{5}{5} d$. The main difference in cost is due to the amount for salaries and wages of attendants, nurses, and servants being larger in this colony than in England. It could have been a useful piece of information if the report, dealing as it does with so many attractive points of detail and management, had given the relative proportion of attendants, nurses, \&c., to the insane population, for this is an important factor in the safe and successful administration of asylums.

Altogether, the report is highly interesting and instructive, and shows excellent results. It appears, on the face of it, to be an honest record of good and useful administrative and inspectorial work among the insane of New South Wales. 